\title{
Knowledge Acquisition in Complex Systems
}

\author{
Katarzyna Grzybowska ${ }^{1,{ }^{*}}$ and Anna Łupicka ${ }^{2}$ \\ ${ }^{1}$ Poznan University of Technology, Strzelecka 11, 60-965 Poznan, Poland \\ 2 Poznan University of Economics and Business, Al. Niepodległości 10, 61-875 Poznań, Poland \\ *katarzyna.grzybowska@put.poznan.pl \\ anna.lupicka@ue.poznan.pl
}

\begin{abstract}
Knowledge in complex systems (supply networks or inter-organisational networks) is refined, among others, through dialogue, discussion, common experiences and observations. Such a knowledge evolves from dispersed knowledge into a single, consistent resource, difficult to imitate or duplicate in a different system. The method of knowledge acquisition has been discussed in the SECI model. In this paper the model in question has been a point of departure for empirical studies. They present methods of knowledge acquisition in complex systems.
\end{abstract}

Keywords: knowledge, knowledge acquisition, SECI model, complex system

\section{Introduction}

Knowledge in the scope of biology and ecology indicates that survival of a living organism depends on the rate on which it its learning. If the learning rate equals or is faster than the rate of changes occurring in the environment, it has a chance to survive. However, if the learning rate is slower than the dynamics of the occurring changes, the organism perishes short of adaptation [1]. Hence, in the authoress's opinion, the necessity to create and acquire knowledge in such complex systems as supply networks or inter-organisational networks. The knowledge in question is accumulated. It is distributed between and shared by members of a developed system. It operates as a "memory" or a "collective mind of a complex system." It is a resource (capital,) stored like data on a hard disk, is in the state of a constant flow resulting from interactions. Knowledge is the most comprehensive resource of all those which help developing wealth. Knowledge is dynamic, since it is created in social inter-actions amongst individuals and organisations [2, 3]. Two main goals of this paper have been set: (1) to identify the methods of creating knowledge in complex systems, (2) to identify the methods of acquiring knowledge as a result of conversion in complex systems on the basis of own research. The paper has the following structure: Part two discusses the SECI model as a model of creating knowledge in complex systems. Moreover, it presents the results of empirical studies showing methods of acquiring knowledge in such systems. The final part is a summary. The paper is of a scientific-research nature.

\section{Acquiring Knowledge by Means of Knowledge Conversion - SECI Model}

The above-presented rule pertaining to the rate of learning and the rate of changes in the environment also fittingly reflects the supply network or inter-organisational network as complex systems. If the market or socio-political changes are more dynamic than the competences and capabilities of an established system's participants, they will not endure on a turbulent market. Hence constant development and constant learning are a necessity for the participants of such systems.

\subsection{Knowledge Acquisition Methods - a Theoretical Approach}

The SECI Model (Socialization, Externalization, Combination, Internalization,) has been developed by I. Nonak [4]. It refers to the system of knowledge acquisition and sharing [2, 5, 6, 7] (Fig. 1.) This model can be useful in the case of creating and sharing knowledge in complex systems.

Knowledge creation and acquisition can be presented with the use of the four types of knowledge conversion shown in figure 1. The first one is socialisation. It is a complex, multi-faceted learning process. As a result of it, a new firm entering the system learns principles and norms of conduct. As a result of socialisation, companies in a complex system become prepared to and capable of a proper 
conduct (coordinated and consistent with an established concept). A progress from individual knowledge (supply network participant) to group knowledge (entire system) occurs. Externalisation consists in knowledge formalisation and then its exchange and sharing within the entire system. All acquired information is accumulated and becomes a uniform and organised entirety. Externalisation forms a basis for generating new patterns, models, ideas and concepts. Knowledge combination consists in combining both the previously acquired and new knowledge, which is dispersed among various companies. Elements of the available knowledge are selected, organised and integrated in a developed knowledge system. Internalisation consists in accepting received knowledge as one's own. The acquired knowledge, formerly processed, becomes familiarised - used and applied in practice.

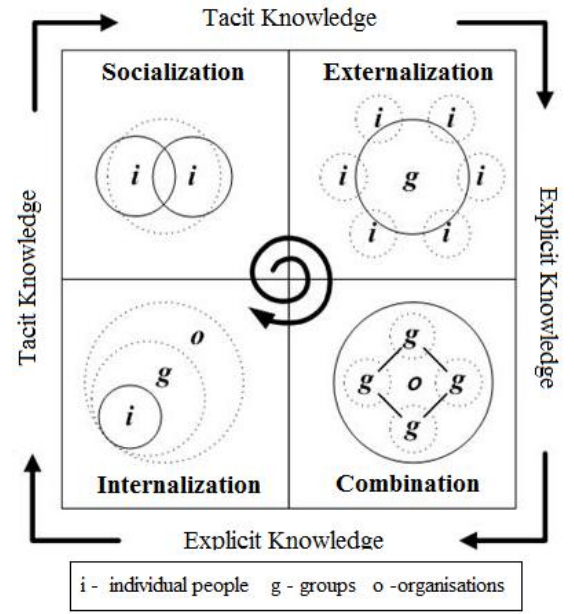

\begin{tabular}{lll}
\hline \multicolumn{1}{c}{ Process } & \multicolumn{1}{c}{ Input factor } & \multicolumn{1}{c}{ Output impact } \\
\hline Internalization & $\begin{array}{l}\text { Publishing of strategy, } \\
\text { Training on operation standards } \\
\text { Training on systemic standards }\end{array}$ & $\begin{array}{l}\text { Motivation to being involved } \\
\text { Improvement of personal skills }\end{array}$ \\
\hline $\begin{array}{l}\text { Exter- } \\
\text { nalization }\end{array}$ & $\begin{array}{l}\text { Personal observations and reflec- } \\
\text { tions concerning basic processes } \\
\text { and their control }\end{array}$ & $\begin{array}{l}\text { Extension of explicit information pool } \\
\text { Contribution to improvement of stand- } \\
\text { ards }\end{array}$ \\
& $\begin{array}{l}\text { Contribution to improvement of strategy } \\
\text { Socialization }\end{array}$ & $\begin{array}{l}\text { Exchange of observations and reflections on process and control } \\
\text { Exchange of experience and personal standards of operation and control }\end{array}$ \\
\hline Combination & $\begin{array}{l}\text { Improvement of standards of operation and control on a base of existent } \\
\text { explicit knowledge } \\
\end{array}$ & $\begin{array}{l}\text { Improvement of strategy on a base of existent explicit knowledge } \\
\text { In particular, analysis of data, establishing new standards }\end{array}$ \\
\hline
\end{tabular}

Fig. 1. The SECI Model [5, 8]

\subsection{Methods of Knowledge Acquisition in Supply Networks - Study Results}

The study was conducted on a sample of 249 business entities in the years 2013-2014. Representatives of micro, small, medium-sized, large and very large businesses participated, 15\%, $18 \%, 25 \%, 22 \%$ and $18 \%$ respectively. They were both public and private sector enterprises: $18 \%$ public and $82 \%$ private. Their capital structure was as follows: domestic capital $-66 \%$, foreign capital $-16 \%$ and mixed capital $-17 \%$ of all the studied enterprises. $45 \%$ of them were providing services, $25 \%$ were manufacturing companies and $31 \%$ trading companies.

The conducted empirical study revealed that all the presented types of knowledge conversion were used in the examined sample of enterprises operating in complex systems, however, not to an adequate extent (Fig. 2). The relatively low level of socialisation is surprising, as it would seem to be the first stage of creating common knowledge and norms. This refers in particular to the principles of and guidelines for common action. Enterprises freshly joining complex systems often need to undergo an accelerated cycle of education and acquisition of the standards, principles and roles in force in order to correctly realise commissioned tasks and activities required from them. This is a process of introducing a novice into an often hermetic environment $-\mathrm{a}$ system. The resulting conclusion is that the socialisation process does not occur in about $38 \%$ of the examined community. This generates problems in the system, connected, among others, with (1) a misperception of and maladjustment to norms and collaboration models, and (2) the exclusion from the created system due to a permanent incompatibility with an acquired model (e.g. proceeding method).

The empirical study reveals that about $43 \%$ of the examined community does not undertake dialogue and share their knowledge in the externalisation process, despite the fact that conceptual knowledge developed upon the knowledge and experience of the system participants is the result of the externalisation process. 


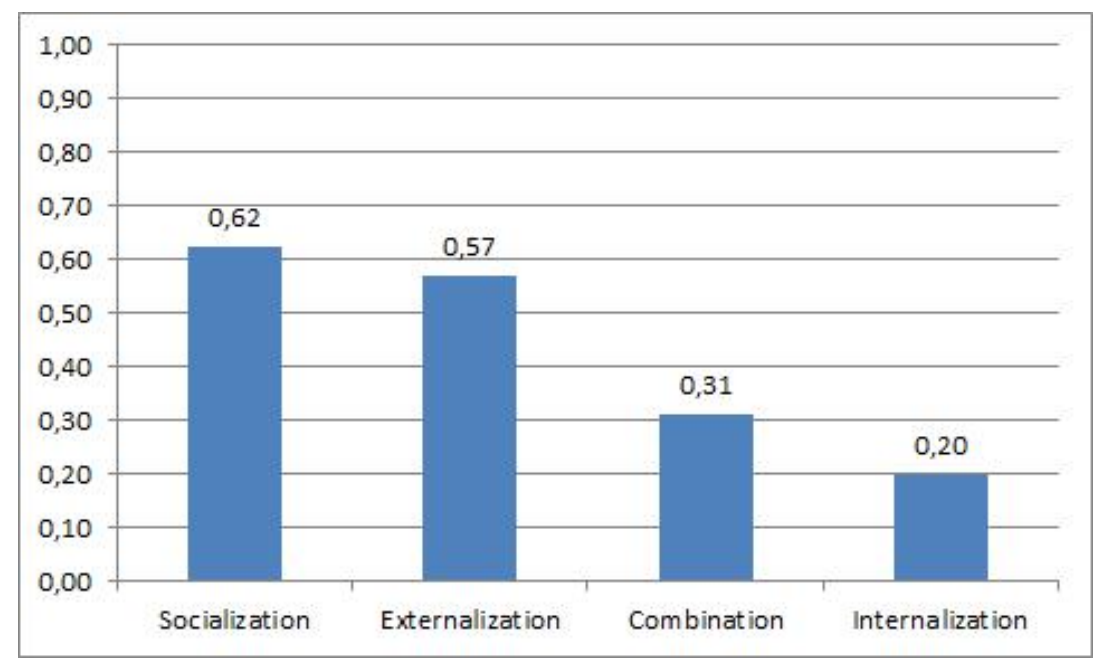

Fig. 2. Methods of knowledge acquisition as a result of knowledge conversion; own elaboration

Systematised knowledge is acquired in the process of combination. Therefore a database (system) of already acquired and new knowledge is created. It forms so-called knowledge repositories, which facilitate access to organised documents and other information resources. They are web platforms dedicated to the indicated complex systems. In $31 \%$ of the examined community the practice confirms the fact of creating knowledge databases. Their lack in a complex system results in an operational and organisational memory hiatus of the system. Another result is the inability to reproduce the best practices.

The smallest number (only $20 \%$ of the examined community) admit the internalisation process, which manifests itself in learning and applying operational (procedural) knowledge. This knowledge is of automated nature: when we possess the procedural knowledge, the know-how, we perform the procedure of an action's implementation. This means that we use generalised rules and acquired procedures. Lack of the internalisation implementation process manifests itself in the lack of knowledge in the scope of the process course and the proceeding methods. However, without the combination process, the internalisation process is impossible. Complex systems are dynamic systems which transform themselves and change their structure, therefore a lack of a knowledge base results in the fact that the system "forgets" a previously used knowledge.

\section{Knowledge Acquisition as a Result of Knowledge Conversion and the Nature of the System}

Similarly to any other organisational form, a complex system, such as a supply network or an inter-organisational network, has its strengths and weaknesses. Theoretical assumptions imply that collaboration in complex systems ensures, among others [8]: (1) better effectiveness and operational flexibility, (2) more effective exchange and mutual use of the resources and competences that are not readily available, (3) information exchange promoting decisions' promptness and accuracy, (4) mutual learning and acquiring new knowledge.

According to K. Perechuda, the capabilities of creating new knowledge in a network depend on the type of the system. Two different types can be distinguished: a friendly one and an absorbing one [9]. A friendly network makes space for the independent generating of latent knowledge. As can be expected, knowledge and information are communicated spontaneously. It also allows realisation and mutual penetration of autonomic projects. Such a network uses the concept of the partial participation of an enterprise in a complex system. Enterprises acting in friendly systems take different actions for other more or less consistent systems, engaging in each such an action to a different degree [10]. Friendly networks are also characterised by the multitude of integrating enterprises responsible for various competences in a network.

On the other hand, an absorbing network imposes standards in the scope of open knowledge. Knowledge is rationed. It manifests itself in the concentration of information and rare, valuable 
knowledge resources by a leader or an integrator of a complex system. The result is a quasi-monopoly - an asymmetry in the possessed information resources and the irregularity in the communicated information. The protection of information is in the interest of the enterprise. Projects and actions are imposed by the enterprise being a leader of integrator. In such a case key competences are also restricted to the integrator firm.

An empirical study revealed that in the studied community as many as $84 \%$ are organisations operating in friendly systems. It was also revealed that that in friendly systems, in comparison to absorbing systems, a greater share of socialisation occurs (Fig. 3a, 3b) $(65 \%$ - a friendly system; up to $51 \%$ - an absorbing system.) It should be expected that enterprises collaborating in a friendly system to a greater degree mutually determine common norms and procedures as partners. The socialisation process occurs in absorbing systems, too, but imposing collaboration terms on other participants of the system by a leader should be expected.
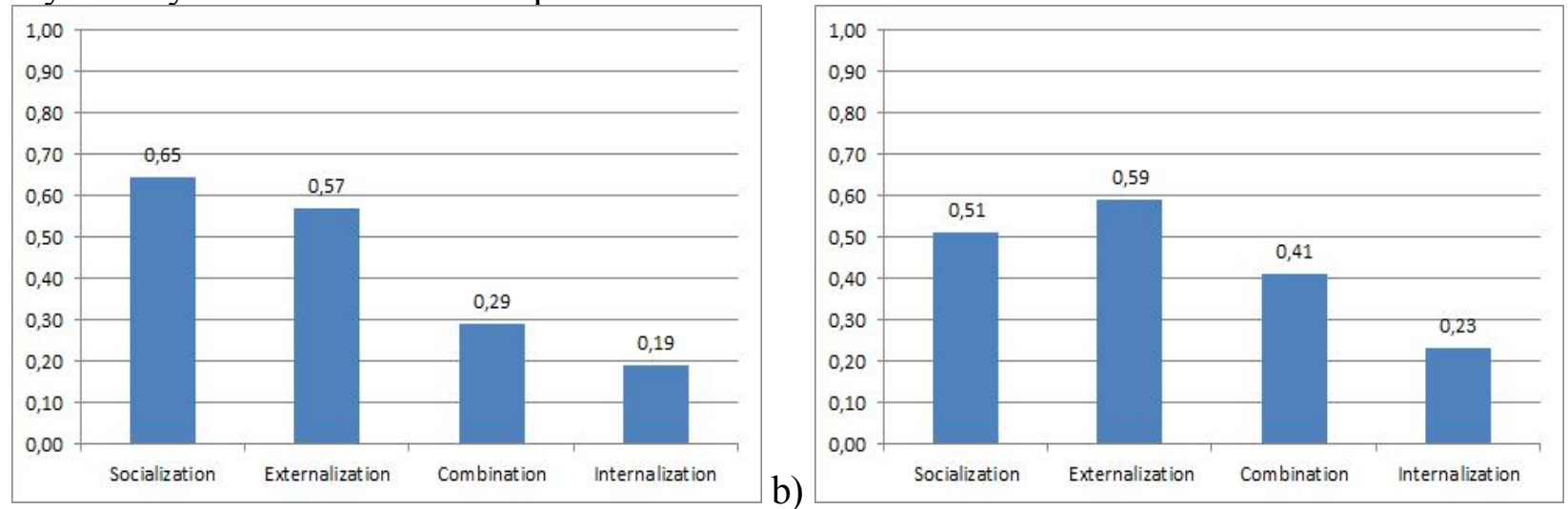

Fig. 3. Methods of knowledge acquisition resulting from knowledge conversion a) in friendly systems, b) in absorbing systems; own elaboration

In the studied community approximately the same percentages of enterprises in friendly and absorbing systems are involved in the externalisation processes (Fig. 3a, 3b.) Formalised knowledge is being accumulated. However, in the case of friendly systems, we can also talk about sharing a uniform and systematised knowledge of all the system participants. In the case of absorbing systems, knowledge is formalised, but the resources are not shared. Although new patterns and concepts are developed, they are retained as own resources of the developed complex system's leaders.

A greater percentage of enterprise in the studied community realising the combination and internalisation processes exists in absorbing systems (Fig. 3b.) This probably results from the dominant role and status of such an enterprise.

\section{Conclusions}

Knowledge becomes a key determinant of the development potential of enterprises and complex systems built by them. The enterprises' participation in a complex system can be an important condition of success and development. This is possible through the access to knowledge in a given system. As an object of exchange in supply networks or inter-organisational networks, the knowledge available in complex systems is much more powerful than the concealed or isolated knowledge. The growing importance of complex systems and the "onlined" knowledge indicates that belonging or not belonging to them is increasingly significant. However, the conducted empirical study reveals that the access to knowledge and sharing it is not obvious and free. In order to be useful, knowledge should be "live", therefore up-to-date and usable. The study shows that meeting these conditions is often difficult in the economic practice.

\section{Acknowledgement}

Presented research works are carried out under the project - WIZ - DS 2016 Poznan University of Technology. 


\section{References}

[1] M. Pedler, T. Boydell, J. Burgoyne: The Learning Company, Studies in Continuing Education Vol. 11, Iss. 2, pp. 91-101, DOI: 10.1080/0158037890110201, (1989)

[2] I. Nonaka, R. Toyama, N. Konno: SECI, Ba and Leadership: A unified model of dynamic knowledge creation', Long Range Planning,33, pp. 5-34, (2000)

[3] Chen Ye-Wu: The Tri-spiral-SECI Model of Knowledge Innovation, Information Science, 2, (2005)

[4] I. Nonaka: The Knowledge-Creating Company, Harvard Business Review, November-December, pp. 96-104, (1991)

[5] Nonaka I., Takeuchi H.: The knowledge-creating company, New York, Oxford University Press, (1995)

[6] J.L. Rice, B.S. Rice: The applicability of the SECI model to multiorganisational endeavours: an integrative review, International Journal of Organisational Behaviour, 9 (8), pp. 671-682, (2003)

[7] K. Grzybowska, B. Gajdzik: SECI model and facilitation on change management in metallurgical enterprise, Metalurgija, 52 (2), pp. 275-278, DOI: 65.01:669.013.003:658.5:658.8=111, (2013)

[8] J.M. Myszewski, On Nonaka's dynamics of Knowledge Management, Research in Logistics \& Production, 1, pp. 59-70, (2013)

[9] K. Perechuda, Dyfuzja wiedzy w przedsiębiorstwie sieciowym. Wizualizacja kompozycja, Wyd. A.E im. O. Langego, Wrocław (2007)

[10]A. Awasthi, K. Grzybowska: Barriers of the supply chain integration process, Logistics Operations, Supply Chain Management and Sustainability, P. Golinska (ed.) Springer International Publishing pp. 15-30, DOI: 10.1007/978-3-319-07287-6_2, (2014) 